\title{
A promoção do Letramento Acadêmico em uma disciplina de escrita: contexto universitário brasileiro
}

\author{
Bruna Vieira
}

Resumo.

Em tempos de Publish or Perish, as habilidades de escrita acadêmica, especialmente em língua inglesa, são cobradas de pesquisadores de todas as áreas do conhecimento ao redor do mundo. Apesar dessa necessidade, um número restrito de cursos de um número ainda menor de universidades brasileiras oferecem disciplinas de escrita acadêmica, levantando o debate sobre a necessidade de multiplicação de disciplinas dessa natureza, e sobre a sua eficiência em preparar os alunos para a comunicação acadêmica. A presente pesquisa teve por objetivo investigar os potenciais da disciplina Metodologia Científica - Redação e Documentação Técnica em promover o letramento acadêmico de graduandos em Ciência da Computação de uma universidade pública brasileira. Para tanto, incialmente, uma investigação quantitiva e qualitativa foi realizada a partir da aplicação de um questionário a 30 egressos da disciplina. A análise das respostas dos alunos mostrou a necessidade de aprofundamento da investigação qualitativa por meio de uma entrevista com a docente e da análise de documentos teóricos e institucionais que regulam e embasam as práticas pedagógicas da disciplina. Os dados levantados nas três investigações foram analisados com base nos Novos Estudos do Letramento e na perspectiva sociorretórica de ensino de gêneros. Os resultados indicam pouco potencial da disciplina em promover o letramento acadêmico dos alunos, uma vez que o ensino se desenvolve com base em perspectivas tradicionais de ensino de escrita.

Palavras-chave:

letramento acadêmico; ensino baseado em gêneros; graduandos em Ciência da Computação 


\section{Academic Literacy Promotion in a Writing Course within a Brazilian University}

Abstract. Publish or Perish times demand academic writing skills from researchers of all fields throughout the globe. Despite it, few disciplines of an even fewer number of Brazilian universities have academic writing courses in their syllabus, which raises the discussions about whether this type of course should be implemented by every discipline, and whether it represents a useful and efficient way of preparing students to academic communication. The present research aimed at investigating the potentiality of the course Metodologia Científica - Redação e Documentação Técnica in promoting academic literacy of Computer Science undergraduate students from a public Brazilian university. To do so, a quantitative/qualitative investigation was conducted through a questionnaire, answered by 30 ex-students from the discipline. The results showed a need of deepening the qualitative investigation, by means of interviewing the Professor and of analyzing theoretical and institutional documents, which regulate the discipline. Data analysis was grounded on New Literacy Studies and Sociorethoric Approach to Genre; and it showed little potential from the course to promote students' academic literacy, since it is based on traditional approaches to teaching writing.

Keywords: Academic literacy; genre-based teaching; Computer Science undergraduate students

\section{La promotion de la Littéracie Universitaire dans un cours de écriture d’une université brésilienne}

Résumé. En temps de Publish or Perish, les capacités d'écriture universitaire sont exigées des chercheurs de tous les domaines de la connaissance autour du monde, particulièrement dans la langue anglaise. Malgré ce besoin, un nombre limité de cours d'un nombre toujours plus petit d'universités brésiliennes offrent les cours d'écriture universitaire, cela attire l'attention sur le débat du besoin de multiplication des disciplines de cette nature et sur son efficacité dans la préparation des étudiants pour la communication universitaire. Cette recherche avait comme l'objectif d'examiner les potentiels du cours intitulé Metodologia Científica - Redação e Documentação Técnica de promouvoir la littéracie universitaire des étudiants des Sciences Informatiques d'une université publique brésilienne. D’abord, une recherche quantitative et qualitative a été réalisée à partir de l'application d'un questionnaire à 30 étudiants sortir du cours. L'analyse des réponses des étudiants a montré le besoin d'approfondir l'enquête qualitative par une interview avec le professeurs et par l'analyse des documents théoriques et institutionnels qui règlent les pratiques pédagogiques de la discipline. Les données soulevées dans les trois enquêtes ont été analysées sur la base des Nouveaux Études de Littéracie et sur la perspective Sociorhétorique des genres textuels. Les résultats indiquent peu de potentiel de la discipline dans la promotion de la littéracie universitaire des étudiants, puisque l'enseignement est développé sur la base des perpectives traditionelles de l'enseignement de l'écriture.

Mots-clés: Littéracie universitaire; enseignement des genres; étudiants des Sciences Informatiques

\section{La promoción de Letramento Académico en una disciplina de escrita de una universidad brasileña}

Resumen. En tiempos de Publish or Perish, las habilidades de escribir textos académicos, particularmente en inglés, son cobradas de investigadores de todas las áreas de conocimiento en todo el mundo. A pesar de esa necesidad, un número pequeño de cursos de un número más pequeño de universidades brasileñas ofrecen disciplinas de escrita académica, levantando el debate sobre la necesidad de multiplicar disciplinas de esa naturaleza y sobre su eficiencia en preparar los universitarios para la comunicación académica. La presente investigación tuvo por objetivo pesquisar los potenciales de la disciplina Metodologia Científica - Redação e Documentação Técnica en promover el letramento académico de los universitarios del curso en Ciencias de la Computación de una universidad pública brasileña. Para tal, una investigación cuantitativa y cualitativa fue realizada mediante la aplicación de un cuestionario a 30 egresados de la disciplina. Los resultados mostraron la necesidad de una profundización de la investigación cualitativa a través de una entrevista con la docente, y de un análisis de textos teóricos y institucionales que rigen y sustentan las prácticas pedagógicas de la disciplina. Los datos fueron analizados sobre la base de los Nuevos Estudios de Letramento y de la perspectiva Socio-retórica de enseñanza de los géneros. Los resultados indican escaso potencial de la disciplina en promover el letramento académico de los alumnos, puesto que la enseñanza de la lengua escrita se realiza sobre la base de las perspectivas tradicionales.

Palabras clave: Letramento académico; enseñanza de escrita por medio de géneros textuales; graduandos de Ciencias de la Computación 


\section{Introdução}

Em ambiente acadêmico, a publicação de artigos científicos é o principal meio de contribuição de pesquisadores para a sua área de atuação, o que fomenta discussões e, consequentemente, leva à evolução do conhecimento e ao reconhecimento dos pesquisadores em sua comunidade (Aranha, 2009). Entretanto, apesar da importância desse gênero para a comunidade acadêmico-científica em geral, no Brasil, conforme Ramos (2008), poucos cursos oferecem disciplinas que orientem os alunos sobre as especificidades do discurso acadêmico, seja para produção ou consumação de gêneros, orais ou escritos, em língua materna ou estrangeira.

Para o curso de Ciência da Computação, um dos cinco cursos mais procurados por vestibulandos (Vieira, 2014) atualmente, essa realidade não se faz diferente, o que, além de dificultar a contribuição de pesquisadores brasileiros na área, ainda limita a participação dos alunos nas variadas atividades acadêmicas, especialmente nas que envolvem a escrita. Há, no entanto, algumas universidades públicas que oferecem disciplinas em nível de graduação com o objetivo de preparar os alunos para o uso de gêneros relevantes para a atuação discente ao longo do curso e para a realização e divulgação de pesquisas, como é o caso da universidade em que a presente pesquisa foi realizada.

Localizada no interior de São Paulo, trata-se de uma das mais conceituadas universidades públicas do Brasil, e que oferece o curso de Ciência da Computação em nível de graduação e pós-graduação. O curso da graduação possui, dentre as 24 disciplinas obrigatórias, a disciplina Metodologia Científica - Redação e Documentação Técnica, oferecida no primeiro semestre do curso. Enquanto objeto de nosso estudo, o objetivo da presente pesquisa era verificar as potencialidades da disciplina em promover o letramento acadêmico (Corrêa, 2011) dos alunos.

Para tanto, um questionário foi aplicado a 30 ex-alunos, uma entrevista semi-estruturada foi realizada com a docente da disciplina, e textos teóricos e prescritivos que fundamentam e orientam suas práticas pedagógicas foram analisados. Os dados oriundos dos três instrumentos de coleta de dados foram analisados e interpretados com base nos Novos Estudos do Letramento (Street, 1984) e na perspectiva sociorretórica de análise e ensino de gêneros (Swales, 1990).

\section{A Perspectiva Sociorretórica de Análise e Ensino de Gêneros na Investigação sobre o Letramento Acadêmico}

A concepção dos usos da escrita (doravante letramentos) como prática social é uma das teses centrais dos Novos Estudos do Letramento (NEL) e é o que fundamenta um dos conceitos mais importantes dessa corrente teórica: o de Modelo Ideológico 
de Letramento, desenvolvido em contraposição ao conceito de Modelo Autônomo de Letramento (Street, 1984). Indo de encontro às práticas tradicionais de ensino de leitura e escrita, continuamente perpetuadas pelo Modelo Autônomo de Letramento, o Modelo Ideológico prega que as práticas letradas são produtos da cultura, da história e do discurso, e não dependem unicamente de habilidades cognitivas dos alunos para se desenvolverem.

Neste sentido, a língua e o texto, enquanto prática e produto social, são permeados por padrões sociais que variam a depender do contexto, e que, por isso, só podem ser compreendidos a partir de uma análise desse contexto imediato de uso. Assim, o ensino da leitura e da escrita deve contemplar questões políticas, ideológicas e sociais, além de questões linguísticas, discursivas e retóricas para potencializar a promoção do letramento junto aos alunos (Magalhães, 2012).

O conceito de gêneros, concebido por Bakhtin (1981), aparece como uma adequada ferramenta pedagógica para os propósitos dos NEL. Ao definir gêneros como tipos relativamente estáveis de enunciados, o autor explica que em cada esfera da atividade humana há um comportamento social, objetivos particulares e formas específicas de se comunicar para o alcance desses objetivos. A recorrência da situação e das formas de organizar a linguagem faz surgir o gênero, que molda as formas de se comunicar e é moldado por quem o utiliza. Assim, os gêneros seriam a materialização de ação social, objetivos comunicativos e usos linguísticos de determinada cultura em uma situação comunicativa específica.

A partir deste conceito de gêneros, e com base em estudos do folclore, estudos literários e retórica sobre o mesmo conceito, Swales (1990) criou uma metodologia sociorretórica para a análise e o ensino de gêneros no ambiente acadêmico. Segundo esta metodologia, a análise e o ensino de um determinado gênero devem partir de uma compreensão detalhada da comunidade acadêmica que Ihe faz uso, sua configuração política, o léxico específico por meio do qual se comunicam, e, especialmente, dos propósitos comunicativos vinculados aos usos dos gêneros por essa comunidade. Em seguida, uma análise textual de exemplares do gênero investiga regularidades retóricas e linguísticas e as interpreta à luz dos conhecimentos levantados sobre a comunidade e seus propósitos comunicativos.

Essa metodologia de análise de gêneros, proposta pela sociorretórica, provê aos professores uma maneira de compreender como a linguagem é usada como um recurso comunicativo (Hyland, 2004), e, a partir disso, elaborar tarefas pedagógicas de modo a facilitar essa compreensão por parte dos alunos. Já em contexto de pesquisa, conforme evidenciamos neste trabalho, pode oferecer um embasamento teórico para analisar o potencial de determinada prática pedagógica em promover o letramento acadêmico dos alunos. 


\section{Metodologia}

A presente pesquisa caracteriza-se como um estudo de caso de caráter híbrido. O estudo de caso, segundo Ventura (2007), é uma modalidade de pesquisa, cuja escoIha do objeto de estudo é definida pelo interesse em casos individuais; e cujo objetivo pode ser compreender questões mais amplas, a fim de orientar pesquisas posteriores. De fato, a presente pesquisa se insere em um contexto maior de investigação, orientado a compreender os eventos de letramento nos quais brasileiros pós-graduandos em Ciência da Computação necessitam se engajar por intermédio da língua inglesa, a fim de elaborar um curso online de Inglês para Fins Acadêmicos ${ }^{1}$. A investigação deste estudo de caso se justifica na medida em que busca por informações a respeito da instrução que graduandos em Ciência da Computação de uma universidade pública brasileira receberam sobre leitura e escrita acadêmica na disciplina Metodologia Científica - Redação e Documentação Técnica, e como ela pode ter contribuído para a promoção do letramento acadêmico desses alunos.

Tendo em vista o contexto em que a presente pesquisa se desenvolve (o ambiente escolar) e todo o dinamismo presente nele, em que, quase sempre, há a ação de múltiplas variáveis do fenômeno educacional, agindo e interagindo ao mesmo tempo, um fluxo linear de pesquisa não se justificaria (Rivero, 1999). Assim, fazendo uso de três procedimentos de coleta, bem como de métodos quantitativos e qualitativos de análise, esta pesquisa buscou triangular os dados a fim de obter maiores informações acerca das práticas pedagógicas realizadas na disciplina em questão, e suas potencialidades em promover o letramento acadêmico dos alunos, considerando a visão dos próprios alunos sobre sua experiência na disciplina, as expectativas e os objetivos da docente para com a disciplina e para com o ensino de leitura e escrita acadêmica, e as bases teóricas e prescritivas em que ela baseia sua prática.

Como o interesse maior das pesquisas conduzidas pela pesquisadora se concentra nos alunos de Ciência da Computação e o desenvolvimento de seu letramento acadêmico, o primeiro passo na presente pesquisa dedicou-se a investigar a percepção dos próprios alunos referente à sua experiência discente na disciplina. Para tanto, um questionário foi aplicado a 30 ex-alunos, com o objetivo de levantar informações sobre seu nível acadêmico, o conteúdo abordado na disciplina, a abordagem de ensino adotada pela professora e as impressões pessoais dos alunos sobre o quanto essas aulas teriam contribuído em sua preparação para a comunicação acadêmica. Com um total de sete questões - sendo três fechadas, duas abertas e duas mistas - o questionário possibilitou uma análise quantitativa e qualitativa dos dados.

A entrevista com a docente da disciplina, realizada com base no modelo semiestruturado (Belei, Gimeniz-Pachoal, Nascimento, \& Matsumoto, 2008), buscou identificar 
os objetivos pedagógicos traçados pela professora para a disciplina, bem como as práticas pedagógicas tomadas por ela para alcançá-los; e representa o segundo passo na realização desta pesquisa. Para tanto, foi questionado à professora a respeito do conteúdo do curso, como ele é escolhido, como ele é abordado e o que a professora espera que os alunos sejam capazes de fazer ao término da disciplina. Fora estas informações pré-planejadas, no decorrer da entrevista foi possível verificar informações a respeito (1) da formação da professora e como ela relaciona a sua formação à prática pedagógica que realiza na disciplina; e (2) os objetivos pedagógicos prescritos pelo departamento de Ciência da Computação para a disciplina e como o nome da disciplina reflete ou não esses objetivos. Todas essas informações contribuiram para explicar alguns porquês e comos da prática pedagógica por meio da qual o ensino é realizado.

Por fim, uma análise textual foi realizada, a qual buscou identificar teorias linguísticas e abordagens de ensino que basearam a criação da disciplina e que fundamentavam as práticas pedagógicas da docente. Os textos utilizados correpondem (i) à ementa da disciplina, disponível no Plano Pedagógico para o curso de Bacharelado em Ciência da Computação da universidade em questão; (ii) às Diretrizes para Apresentação de Monografia, elaborado pela professora e mais dois docentes do curso; (iii) a um texto entitulado Projeto Final - Normas e Procedimentos para o ano de 2012 (ano em que a pesquisa fora realizada), disponível no endereço virtual da universidade; e (iv) a um artigo científico em língua inglesa sobre orientações para a escrita de artigos e resumos de acordo com a Sociedade Brasileira de Computação (SBC)².

Em pesquisa qualitativa, a análise dos dados tende a seguir um processo indutivo (Bogdan e Biklen, 1982 apud Rivero, 1999), por isso, deve existir um quadro teórico que oriente a análise de dados. Assim, uma vez que o método utilizado em grande parte da análise dos dados foi qualitativo-interpretativo, os pressupostos teóricos dos NEL e os pressupostos metodológicos da perspectiva sociorretórica de gêneros a orientaram.

\section{Análise e Interpretação dos Dados}

\subsection{As percepções dos alunos sobre a disciplina}

O questionário, como mencionado, foi o instrumento de coleta de dados utilizado para levantar informações que possibilitassem acessar o potencial da disciplina em promover o letramento dos alunos a partir de suas próprias percepções sobre as aulas. Pessoalmente, ao final das aulas da graduação do período da manhã, durante uma semana, os alunos foram convidados a respondê-lo.

$\mathrm{Na}$ ocasião, foram instruídos quanto à natureza e os objetivos da pesquisa, e, aqueles que aceitaram participar, assinaram um termo de consentimento (localizado no cabeçalho do questionário) para a utilização de suas respostas nesta pesquisa. 
Ao todo 30 alunos responderam ao questionário, 26 homens e 4 mulheres, e todos já haviam concluído a disciplina, como é possível verificar em suas respostas à questão 1 (Quadro 1), cujo objetivo era identificar o estágio acadêmico em que os alunos se encontravam à época.

Quadro 1: Questão 1 do questionário

\begin{tabular}{|c|c|c|c|}
\hline \multicolumn{3}{|c|}{ Questão 1 - Você está em que ano do curso de Bacharelado em Ciência da Computação? } \\
\hline Ano & Primeiro & Terceiro & Quarto \\
\hline Quantidade & 6 & 8 & 16 \\
\hline
\end{tabular}

Fonte: Autora

As perguntas sobre o conteúdo da disciplina (questões 2, 3, 4 e 7) revelaram que, a partir da visão dos alunos, (i) a disciplina busca desenvolver ambas as habilidades de escrita e de leitura de textos acadêmicos (Quadro 2); (ii) os gêneros mais utilizados nas aulas são artigo de pesquisa e resumo de artigo de pesquisa (Quadro 3), muito embora a prática de escrita se desenvolva prioritamente apenas na produção do segundo gênero (quadro 4); e (iii) não há um trabalho de preparação para a prova de mestrado.

Quadro 2: Questão 2 do questionário

\begin{tabular}{|c|c|c|c|c|}
\hline $\begin{array}{r}\text { Questão } 2 \text { - Quais das habilidades abaixo foram praticadas por você durante a execução das } \\
\text { atividades propostas na disciplina Redação e Documentação Técnica. }\end{array}$ \\
\hline Alternativas & Leitura & Escrita & Ambas & $\begin{array}{c}\text { Não } \\
\text { Responderam }\end{array}$ \\
\hline Quantidade & 5 & 5 & 19 & 1 \\
\hline
\end{tabular}

Fonte: Autora

Esta união entre atividades de leitura e escrita, evidenciada pela resposta da maioria dos alunos (19) que assinalou ambas as alternativas na questão 2, pode indicar um fator positivo na promoção do letramento acadêmico dos alunos. Muito pesquisadores em educação abordam a relação instrínsica entre leitura e escrita - como Bazerman, Simon e Pieng (2014) na área de estudos de gêneros - evidenciando a importância de ambas as habilidades no processo de desenvolvimento de cada uma. Um bom desempenho na leitura de textos acadêmicos vem a contribuir para a aprendizagem de escrita acadêmica, pois, como afirma Aranha (2002), leitura consciente pode contribuir para escrita consciente. Segundo a autora, por meio da leitura, os alunos têm contato com aspectos lexicais, temáticos, argumentativos e de registro comuns em sua área de atuação e, assim, necessários para a escrita dos textos.

Disciplinas de redação acadêmica, oferecidas, geralmente, no primeiro ano, tendem a ter como objetivo, preferencialmente, o desenvolvimento das habilidades de 
escrita dos alunos em gêneros exigidos nas várias disciplinas ao longo curso (Russell, Lea, Parker, Street, \& Donahue, 2009); além da preparação dos alunos para a realização e divulgação de pesquisas. Os dados da questão 3 indicam uma possível consistência entre esses objetivos e a prática pedagógica da disciplina percebida pelos alunos, uma vez que, tanto os gêneros exigidos em outras disciplinas, como projeto de pesquisa, relatório de pesquisa e monografia, quanto os gênero de divulgação de pesquisa (artigo acadêmico e resumo) foram apontados pelos alunos como conteúdo abordado nas aulas.

Quadro 3: Questão 3 do questionário

\begin{tabular}{|c|c|}
\hline \multicolumn{2}{|c|}{ Questão 3: Assinale os tipos de texto abaixo } \\
com os quais você teve contato durante a disciplina. \\
\hline Gêneros & Quantidade \\
\hline Artigos Acadêmicos & 26 \\
\hline Resumos/Abstracts de Artigos & 26 \\
\hline Projetos de Pesquisa & 17 \\
\hline Monografias & 15 \\
\hline Relatórios/Relatos de Pesquisa & 15 \\
\hline Manuais Técnicos & 7 \\
\hline Anúncios Publicitários & 3 \\
\hline Dissertações de Mestrado & 1 \\
\hline Teses de Doutorado & 1 \\
\hline Outros. Especifique & 0 \\
\hline
\end{tabular}

Fonte: Autora

Uma análise quantitativa dessas respostas indica, no entanto, uma possível inversão de prioridades, já que a maioria dos alunos (26) anotou os gêneros de divulgação de pesquisa, e apenas metade deles (uma média de 16) lembrou-se de ter trabalhado com gêneros demandados nas outras disciplinas durante as aulas da disciplina em questão. Essa inversão, a partir de uma análise qualitativa, pode indicar tanto um interesse maior por parte dos alunos nesse conteúdo, fazendo-os se lembrarem prioritariamente deles, quanto um real foco maior da professora em lecionar esses gêneros. Ambos possivelmente justificados pela pressão, comumente conhecida como Publish or Perish, que alunos, professores, departamentos e universidades sofrem diariamente para publicarem resultados de pesquisa (Rego, 2014). 
Uma melhor visualização sobre os conteúdos lecionados e sobre como eles possibilitam o alcance dos objetivos da disciplina será possível ao considerar o conteúdo programático elaborado pela professora, bem como os textos institucionais que regulam o funcionamento da disciplina. Essa discussão, portanto, será retomada futuramente.

\section{Quadro 4: Questão 4 do questionário}

Questão 4: Dentre os tipos de texto assinalados acima, especifique aqueles que você teve de produzir (escrever) como parte de um exercício, atividade, trabalho ou prova durante a disciplina.

\begin{tabular}{|c|c|}
\hline Gêneros & Quantidade \\
\hline Resumos/Abstracts de Artigos & 15 \\
\hline Projetos de Pesquisa & 11 \\
\hline Artigos Acadêmicos & 2 \\
\hline Relatórios/Relatos de Pesquisa & 2 \\
\hline Monografias & 1 \\
\hline Nenhum & 3 \\
\hline Não se lembravam & 1 \\
\hline Não responderam & 2 \\
\hline
\end{tabular}

Fonte: Autora

A análise dos dados oriundos das respostas à questão 4 evidencia uma possível inconsistência nas práticas pedagógicas da disciplina que pode interfirir na promoção do letramento acadêmico dos alunos. Como evidenciado no quadro 4 acima, resumo/ abstract de artigos de pesquisa foi o gênero mais assinalado (15 alunos) como resposta para a questão referente à produção escrita nas atividades da disciplina. Embora muito relevante para a prática de divulgação de pesquisas, uma vez que pode compor base de dados no país e no exterior (Biasi-Rodrigues, 2009), é um gênero geralmente produzido no final de pesquisas, já que veicula as principais informações de cada etapa da pesquisa realizada (Gil, 2014). Assim, é possível supor que as atividades de escrita do gênero não tenham tido motivações sociais reais, como propõem os NEL e a perspectiva sociorretórica de gêneros, pois, estando os alunos no primeiro semestre do curso, as chances de eles já terem finalizado a realização de uma pesquisa para a produção do resumo/abstract são mínimas. É preciso, no entanto, novamente, considerar os dados oriundos da entrevista com a docente e da análise textual para uma melhor compreensão dessas práticas pedagógicas. 
Quadro 5: Questão 7 do questionário

\begin{tabular}{|l|c|c|c|}
\hline \multicolumn{4}{|c|}{$\begin{array}{c}\text { Questão 7: Os alunos são preparados para a prova do mestrado } \\
\text { na disciplina de Redação e Documentação Técnica? }\end{array}$} \\
\hline Alternativas & Sim & Não & Não Responderam \\
\hline Quantidade & 10 & 19 & 1 \\
\hline
\end{tabular}

Fonte: Autora

O quadro 5 evidencia que, embora as respostas anteriores dos alunos indiquem um foco da disciplina na preparação dos alunos para a realização e divulgação de pesquisas, ela pode não estar contribuindo para a preparação deles para o exame da pós-graduação - momento acadêmico em que mais se produz os gêneros de divulgação de pesquisa. A análise da entrevista com a professora e dos documentos teóricos e prescritivos possibilitarão verificar com precisão o conteúdo programático da disciplina, entretanto, com base nos dados do quadro 7 é possível inferir que, ainda que a disciplina ofereça atividades para a preparação dos alunos para o mestrado, como sugere a resposta positiva de 10 alunos à questão sobre a disciplina contribuir para a preparação deles para a prova de mestrado, a abordagem utilizada pode não corresponder às necessidades e/ou expectativas dos alunos, uma vez que quase o dobro deles (19) responderam negativamente à questão.

A pergunta sobre a abordagem de ensino de escrita utilizada pela professora nas aulas (questão 5) mostrou que, com base na visão dos alunos, as atividades desenvolvidas em sala dedicam-se, em sua maioria, à formatação de textos, como exposto no quadro 6.

Quadro 6: Questão 5 do questionário

\begin{tabular}{|c|c|}
\hline \multicolumn{2}{|c|}{$\begin{array}{l}\text { Questão 5: Durante a disciplina de Redação e Documentação Técnica, quais aspectos dos } \\
\text { textos eram trabalhados? }\end{array}$} \\
\hline Alternativas & Quantidade \\
\hline Formato (conteúdos obrigatórios, linhas a pular, tipo de letra, espaçamento etc) & 29 \\
\hline Gramática (tempo verbal, preposições, conjunções etc) & 13 \\
\hline $\begin{array}{c}\text { Gênero (Papéis sociais do leitor e escritor, contexto de produção e recepção, } \\
\text { propósitos comunicativos dos textos etc) }\end{array}$ & 10 \\
\hline
\end{tabular}

Fonte: Autora

Esta questão obteve a maior unanimidade nas respostas dos alunos. Vinte e nove dos 30 participantes indicaram ter trabalhado com formatação de textos na disciplina. Embora este seja um aspecto muito importante, especialmente na escrita de artigos e resumos para submissão, aulas de escrita acadêmica não devem se limitar a ele, 
especialmente porque este tipo de informação está geralmente disponível nas diretrizes para autores de periódicos e conferências.

Em pesquisa anterior, conduzimos uma investigação em seis periódicos altamente avaliados $^{3}$ da área a qual revelou que as diretrizes para autores desses periódicos concentram-se em aspectos superciais do texto, tais como estrutura e formatação, deixando escondidas dimensões do letramento (Street, 2010) que costumam ser levadas em consideração na hora da avaliação dos textos por editores e pareceristas. Assim, essas dimensões escondidas, além de questões mais recorrentes na área de ensino de gêneros, como comunidade discursiva e propósito comunicativo dos textos, podem contribuir mais para a promoção do letramento acadêmico dos alunos, do que questões estruturais e formais dos gêneros, que já são disponibilizadas pelas revistas da área. Os dados da entrevista e da análise textual revelarão mais sobre a abordagem de ensino utilizada pela professora em sala.

Por fim, as impressões pessoais dos alunos sobre o potencial da disciplina em promover seu letramento acadêmico foi levantada a partir da questão 6 do questionário. As respostas da maioria dos alunos (20) indicam percepções negativas dos alunos neste quesito, como ilustram as informações no quadro 7.

Quadro 7: Questão 6 do questionário

\begin{tabular}{|c|c|}
\hline $\begin{array}{c}\text { Questão 6: Após o término da disciplina, você se sentiu seguro para elaborar textos } \\
\text { acadêmico-científicos exigidos na sua área de atuação? Por quê? }\end{array}$ \\
\hline Alternativa & Quantidade \\
\hline Sim & 10 \\
\hline Não & 20 \\
\hline
\end{tabular}

Fonte: Autora

Dentre as respostas positivas, dois alunos atribuiram o sucesso da disciplina às qualificações da professora; outros dois alunos apontaram o conteúdo como o fator de satisfação; e outros quatro alunos justificaram sua segurança em escrever textos acadêmicos com base no conhecimento sobre formalização e, principalmente, sobre as regras da Associação Brasileiras de Normas Técnicas (ABNT). Essa justificativa, que suporta as análises das respostas à questão anterior sobre o ensino da disciplina ser baseado em perspectivas tradicionais de ensino, também foi usada por três alunos que responderam negativamente à questão, como o aluno do terceiro ano que respondeu "Porque foi abordado apenas o aspecto técnico da produção textual".

\subsection{As perspectivas pedagógica e institucional sobre a disciplina}

A docente da disciplina com que a entrevista fora realizada era, à época, também coordenadora do curso de bacharelado em Ciência da Computação e já estava há oito 
anos na instituição. Sua formação é na área tecnológica, mas, além das disciplinas da área, lecionava a disciplina de redação desde seu ingresso na universidade. Apesar de não ter formação em comunicação ou linguística, a professora se sente preparada para lecionar a disciplina, uma vez que, segundo ela, o propósito da disciplina deveria ser ensinar metodologia científica aos alunos, e não redação de textos científicos. Assim, de acordo com a professora, o nome da disciplina estaria errado e deveria ser apenas Metodologia Científica.

Apesar dessas impressões da docente a respeito dos objetivos que a disciplina deveria ter, com base em sua descrição sobre as atividades realizadas em sala de aula, é possível constatar que um trabalho de ensino de leitura e escrita acadêmica é realizado. Ademais, a partir dessa descrição, foi possível confirmar quase todas as análises realizadas com base nas respostas dos alunos.

Com relação às habilidades comunicativas desenvolvidas nas aulas e ao conteúdo da disciplina, de fato, leitura e escrita são trabalhadas, e tanto os gêneros exigidos em outras disciplinas quanto os gêneros de divulgação de pesquisa são abordados. Estas constatações não refletem, no entanto, um aspecto positivo das práticas pedagógicas, uma vez que há pouca interatividade entre as atividades de leitura (que se concentram mais nos gêneros artigo de pesquisa e abstract) e de escrita (que se realizam na produção de monografias, prioritariamente). A única exceção parece ser a produção escrita de abstract, mas, segundo a professora, confirmando novamente a análise das respostas dos alunos, o objetivo não é a aprendizagem do gênero, mas do léxico (pois a leitura e a escrita desse gênero se realizam em língua inglesa) e da formatação do texto.

Neste sentido, é possível afirmar que o ensino de redação acadêmica se realiza com base em uma abordagem tradicional, baseada no modelo autônomo de letramento (Street, 1984). A análise dos textos teóricos e do texto prescritivo também permite esta interpretação.

O relato da professora indica que as práticas pedagógicas envolvendo a leitura acadêmica aproximam-se do já antigo "ensino instrumental", uma vez que, com o objetivo de instrumentalizar os alunos para uma leitura rápida em língua estrangeira, por quase cem por cento da biografia do curso ser em inglês, ela desenvolve atividades de compreensão de textos e reconhecimento vocabular com artigos científicos e abstracts. Já as práticas pedagógicas de escrita têm por objetivo "colocar os alunos em contato com os textos técnicos ${ }^{4}$ e sua formatação".

Esses objetivos parecem ir ao encontro daqueles prescritos pela universidade para a disciplina. Segundo a ementa do curso, a disciplina deve abordar "itens básicos para a elaboração e apresentação de trabalho científico." A análise dos textos teóricos reforça essa constatação, uma vez que, tanto as Diretrizes para a apresentação da monografia, quanto o artigo de Nedel, Bordini, Wagner e Huber (2002) concentram-se em descrever estruturalmente os gêneros monografia e artigo científico, respectivamente. 
Embora a professora trabalhe com específicos gêneros ao longo da disciplina, a atenção é mantida no léxico, para os textos em inglês, e na estrutura textual, para os textos em português. Essa abordagem tradicional de ensino de leitura e escrita na qual as práticas pedagógicas da professora parecem se orientar apresenta pouco potencial em promover o letramento acadêmico dos alunos, justificando, portanto, a sensação de despreparo dos mesmos para a escrita acadêmica, mesmo após a participação na disciplina, como evidenciado pela resposta da maioria dos alunos ao questinário. Considerando que os textos técnicos abordados na disciplina são, na verdade, gêneros acadêmicos e, portanto, convenções discursivas socio-hitórico-culturalmente desenvolvidas para a comunicação e para o alcance de objetivos compartilhados pelos membros dessa comunidade, apenas o reconhecimento do léxico ou da estrutura de um texto não capacita os alunos a engajarem-se nesses eventos comunicativos. Pelo menos, não com autonomia e consciência crítica sobre o que e o porquê de estarem lendo ou produzindo determinados textos, sob determinadas convenções (Hyland, 2004).

\section{Conclusões}

A presente pesquisa buscava entender as práticas pedagógicas aplicadas na disciplina Metodologia Ciêntífica - Redação e Documentação Técnica do curso de bacharelado em Ciência da Computação de uma universidade pública brasileira, de modo a verificar seu potencial em promover o letramento acadêmico dos alunos.

A análise predominantemente qualitativa nas três investigações realizadas (questionário, entrevista e análise textual) foi desenvolvida com base nos NEL e na perspectiva sociorretórica de análise e ensino de gêneros. E os seus resultados permitem concluir que, apesar de a universidade em questão oferecer uma disciplina cujo nome vincula a ideia de ensino de leitura e escrita para graduandos em Ciência da Computação, as práticas pedagógicas na disciplina convergem mais para o desenvolvimento de habilidades técnicas dos alunos do que para a promoção de seu letramento acadêmico, culminando, assim, na insegurança e no despreparo deles para a atuação acadêmica por meio do texto escrito.

É relevante mencionar que, como sugerido pela professora, o nome da disciplina mudou para Metodologia Científica no ano de 2015. Uma nova investigação precisaria ser realizada a fim de entender como/se a mudança do nome modificou também as práticas pedagógicas da disciplina. É possível supor, no entanto, que a retirada do nome "Redação" tenha culminado em práticas ainda menos relacionadas à promoção do letramento acadêmico, o que deve ser visto com pesar, já que o movimento deveria ser o oposto, ou seja, multiplicar o número de disciplinas dessa natureza, já que esses alunos, como a maioria dos alunos das universidades públicas brasileiras, são cobrados a ler e a escrever academicamente sem que isso Ihes tenha sido ensinado. 
Nota:

Este artigo insere-se no âmbito da pesquisa de doutorado da autora e financiada pela Fundação de Amparo à Pesquisa do Estado de São Paulo (FAPESP) (processo $n$. 2015/11088-1).

\section{Referências Bibliográficas}

Aranha, S. (2002). A otimização da escrita acadêmica através da conscientização textual. Anais do XXXI Grupo de Estudos Linguísticos do Estado de São Paulo, Marília: Fundação de Ensino "Eurípides Soares da Rocha".

Aranha, S. (2009). The development of a genre-based writing course for graduate students in two fields. In: Bazerman, C.; Bonini, A; \& Figueiredo, D. (Org.). Genre in a changing world (pp. 465-482). Santa Barbara: The WAC Clearinghouse and Parlor Press.

Bakhtin, M. M. (1981). The Dialogic Imagination. Austin: University of Texas Press. [Disponível em \{http:// s3.amazonaws.com/academia.edu.documents/35251261/BAKHTIN-The_Dialogic_Imagination.pd f?AWSAccessKeyld=AKIAJ56TQJRTWSMTNPEA\&Expires=1480492597\&Signature=wgmupefaw NIMQb5Rle9zdgyY\%2FTU\%3D\&response-content-disposition=inline\%3B\%20filename\%3DTHE_ DIALOGIC_IMAGINATION_Four_Essays.pdf\}, consultado em 30/11/2016].

Bazerman, C., Simon, K., \& Pieng, P. (2014). Writing about reading to advance thinking: A study in situated cognitive development. In Writing as a Learning Activity (pp. 249-276). Brill. [Disponível em \{https://www.researchgate.net/publication/297550449_Writing_about_reading_to_advance_ thinking_A_study_in_situated_cognitive_development\}, consultado em 28/11/2016].

Belei, R. A., Gimeniz-Paschoal, S. R., Nascimento, E. N., \& Matsumoto, P. h. V. R. (2008). O uso da entrevista, observação e videogravação em pesquisa qualitativa. Cadernos de Educação, (30), 187 199. [Disponível em \{https://periodicos.ufpel.edu.br/ojs2/index.php/caduc/article/view/1770/1645\}, consultado em 27/11/2016]

Biasi-Rodrigues, B. (2009). O gênero resumo: uma prática discursiva da comunidade acadêmica. In: Biasi-Rodrigues, B. et al (Org.). Gêneros textuais e comunidades discursivas: um diálogo com John Swales. (pp. 49-75) Belo Horizonte: Autêntica.

Corrêa, M. L. G. (2011). As perspectivas etnográfica e discursiva no ensino da escrita: o exemplo de textos de pré-universitários. Revista da ABRALIN, 10(4), 333-356. [Disponível em \{http://www. abralin.org/revista/RVE2/11v.pdf\}, consultado em 26/11/2016]

Flowerdew, J., \& Peacock, M. (2001). Research perspectives on English for academic purposes. Cambridge: Cambridge University Press.

Gil, B. (2014). O gênero acadêmico: resumos nas áreas de Antropologia, Linguística e Ciência Política. Dissertação de Mestrado. São José do Rio Preto: Universidade Estadual Paulista Júlio de Mesquita Filho.

Hyland, K. (2004). Genre and second language writing. Ann Arbor: The University of Michigan Press.

Magalhães, I. (Org.) (2012). Discurso e Práticas de Letramento: Pesquisa Etnográfica e formação de professores. Campinas, SP: Mercado das Letras. 
Ramos, R. C. G. (2008). ESP in Brazil: history, new trends and challenges. In: Krzanowski, M. (Ed.). ESP and EAP in developing and in least developing countries (pp. 68-83). Canterbury: IATEFL. [Disponível em \{http://www.teachingenglish.org.uk/sites/teacheng/files/ESPBrazil_Ramos_.pdf\}, consultado em 23/11/2016]

Rego, T. C. (2014). Produtivismo, pesquisa e comunicação científica: entre o veneno e o remédio. Educação e Pesquisa, 40 (2), 325-346.

Rivero, C. (1999). Etnometodologia na pesquisa qualitativa em educação. Impulso, 9, 113-125. [Disponível em \{http://www.sepq.org.br/llsipeq/anais/pdf/mr2/mr2_5.pdf\}, consultado em 22/11/2016]

Russell, D. R., Lea, M., Parker, J., Street, B., Donahue, T. (2009). Exploring notions of genre in 'academic literacies' and 'writing across the curriculum': approaches across countries and contexts. In: Bazerman, C.; Bonini, A; Figueiredo, D. (Org.). Genre in a changing world. X ed. Santa Barbara, CA: The WAC Clearinghouse and Parlor Press, 395-423. [Disponível em \{http://wac.colostate.edu/ books/genre/chapter20.pdf\}, consultado em 21/11/2016].

Street, B. (1984). Literacy in Theory and Practice. Cambridge: CUP.

Street, B. (2010). Dimensões "escondidas" na escrita de artigos acadêmicos. Perspectiva, 28, 2, 541-567.

Swales, J. M. (1990). Genre Analysis: English in academic and research settings. Cambridge: Cambridge University Press.

Ventura, M. (2007). O estudo de caso como modalidade de pesquisa. Rev Socerj, 20(5), 383-6. [Disponível em \{http://sociedades.cardiol.br/socerj/revista/2007_05/a2007_v20_n05_art10.pdf\}, consultado em 24/11/2016].

Vieira, B. G. A. M. (2014). Passos para a elaboração de um curso de EAP para pós-graduandos em Ciência da Computação. Dissertação de Mestrado, Universidade Estadual Paulista, São José do Rio Preto, São Paulo.

\section{Bruna Vieira}

Doutoranda em Linguística Aplicada pela Universidade Estadual Paulista (Unesp), Instituto de Biociências Letras e Ciências Exatas (Ibilce), Câmpus de São José do Rio Preto, Brasil Pesquisadora visitante do departamento de Educação da Universidade da Califórnia (UCSB), EUA brugabiguto@yahoo.com.br

\section{Correspondência}

Bruna Vieira

R. Cristóvão Colombo, 2265 - Jardim Nazareth, São José do Rio Preto - SP, 15054-000, Brasil

Data de submissão: Julho 2016

Data de avaliação: Outubro 2016

Data de publicação: Julho 2017 